\title{
Temporal Profiles of Urban Lighting: Proposal for a research design and first results from three sites in Berlin
}

\author{
Josiane Meier ${ }^{1, *}$ \\ ${ }^{1}$ Department of Urban and Regional Planning, Technische Universität Berlin, Germany
}

Received 26 November 2017, Accepted 28 February 2018

\begin{abstract}
This paper contributes to fundamental research on outdoor lighting practices by presenting and applying a research design for studying their temporal dimension in complex lightscapes such as those of urban centres. The research design complements existing methods for studying the temporality of lighting (Dobler et al., 2015; Bará et al., 2017): equally based on data collection via time-lapse videos, the design adopts a small-scale, detailed approach by using close-range perspectives to document the on/off patterns of individual light sources as the night progresses. It provides a framework for reading, describing and comparing these temporal profiles of lighting that allows for pinpointing similarities and differences among temporal lighting practices in different places, nights or categories of lighting. In the three examined Berlin areas, on/off-times are clustered, resulting in static and dynamic phases of the night. Midnight is a temporal fault-line, after which full illumination ends as portions of the lights are extinguished. Switch-off times and -rates differ among the three areas and, especially, among the four functional types of lighting that were differentiated: infrastructural and commercial units largely remain on all night, while substantial portions of architectural and indoor lighting are switched off, though at fairly different times. This tentatively indicates that, within one geographic and policy context, the purposes to which lights are put are likely more decisive for their temporality than is their concrete locality, but that heterogeneous local temporal lighting cultures may nonetheless exist - even among similar types of areas within the same city.
\end{abstract}

Keywords: urban lightscapes, temporality, dynamics, method, classification

\section{Introduction}

The past two decades have seen a consolidation of evidence from a broad range of disciplines that artificial outdoor illumination not only has manifold benefits, but also comes with substantial societal and ecological costs and risks. These are commonly subsumed under the term light pollution, and their long-term effects are hardly foreseeable [1;2; 3]. The observation that illumination is rapidly expanding in many parts of the world in terms of both geographic spread and intensity $[1 ; 4 ; 5]$ lends additional urgency to the matter.

As this is a fairly new field of inquiry, knowledge about the underlying lighting practices that structure these developments is still quite limited. A deeper understanding of how much of what types of lighting are used by whom, when, where and why is, however, essential for the establishment of a solid knowledge-base for sustainable planning and policy approaches. Given that the usage of lighting has technical as well as societal dimensions, this demands research in a variety of disciplines; and seeing as lighting practices differ from one context to the next, comparative studies promise to provide insights into local lighting cultures as well as pointers for policy development [6].

This paper contributes to a fuller understanding of lighting practices by focusing on an aspect that has, so far, gone largely unexplored: their temporal dimension. It addresses the question of how the temporality of urban lighting is structured in specific types of areas, and how such temporal lighting practices compare to each other. To this end, it presents and applies a research design that grasps how the employment of lighting changes in

*Meier J, E-mail address: josiane.meier@tu-berlin.de 
terms of its on/off patterns as the night progresses, and carves out similarities and differences among the temporalities of various kinds of lights that compose a lightscape. The design was developed based on, and is geared toward, the analysis of particularly complex lighting situations of limited size, such as those typically found in urban centres. It is kept technically simple and conceptually flexible enough to make it transferable to other locations and compatible with a range of research interests, thereby facilitating comparative and cross-disciplinary studies.

The research design consists of (1) a method of data collection, namely series of photographs taken from elevated locations within the city that allow for detailed identification of different light sources and are assembled into time lapse videos, (2) a method of data extraction that translates the lights in the images into temporal units and identifies their individual temporal profiles as time series of on/off data, and (3) a framework for data analysis that provides a vocabulary and concepts for characterising and comparing the temporal profiles of different categories of lighting.

Close-range time lapse videos allow for a continuous documentation of the changes that lightscapes exhibit, and for a direct identification of the light sources causing these changes. This sets them apart from two other means of gaining information on the temporality of lighting: Continuous sky quality measurements can document the development of lights' cumulative effects on the night sky throughout the night [7; 8; 9]. As indirect assessments, they cannot, however, differentiate the light sources behind the observed trends. Comparisons of aerial images can provide indications as to when certain (groups of) lights are switched on/off [10; 11]. However, as they are commonly snapshots from individual points in time on different nights, they cannot provide continuous timelines, and given the perspective from above, identifying specific light sources can be difficult.

The research design presented here is complementary to the approach developed by Dobler et al. [12] for studying urban rhythms: Both share the same method of data collection and look at on/off times of urban lighting. Significant differences exist, however, in the aims of the research, and, as a result, in terms of perspective and scale: Dobler et al. take a broad view of the city from a removed vantage point in order to capture a large number of household and office windows to statistically soundly derive information on the "pulse of the city”. In contrast, I look into urban hotspots of lighting in order to identify the light sources they are composed of with as much precision as possible. It is equally complimentary to the approach presented by Bará et al. [13], which estimates the relative contribution of different types of lighting - street, vehicle and domestic to overall sky brightness over the course of the night by using series of images to extract the sources' radiance. Accordingly, sections of lightscapes containing specific types of lighting are sought out, rather than targeting specific types of urban areas.

The research design is described in section 2, as is its application to the three Berlin case studies with which it was developed. The results of this analysis are presented in section 3. In section 4, I discuss the proposed research design and findings, and conclude in section 5.

\section{Research Design}

Three urban centres in Berlin, Germany, served as a laboratory for developing the research design and demonstrating the type of results it can achieve. This section provides guidelines for applying the research design. It highlights options and issues to be considered, and illustrates the choices made for the Berlin cases.

\subsection{Areas of Study}

The research design is geared toward decrypting the temporalities of high-density lightscapes ${ }^{1}$ in areas of limited size, as typically found in urban centres. It is, however, not principally limited to these and can equally be applied to other types of areas. For interpreting the results, it is relevant to reflect factors that are likely influential for (temporal) lighting practices, particularly the areas'

- geographic location and corresponding sunset-/sunrise times,

- temporal policies, in general and for lighting (especially curfews), and

- characteristics as regards their functions, architecture and overall temporal character.

Here, the interest was to gain pointers for factors that potentially influence temporal lighting practices by exploring how these compare in areas that share a wide range of key similarities, but contrast in selected respects. As all three areas - Alexanderplatz, Potsdamer Platz and Hackescher Markt - are located in Berlin, they share a single geographic and policy context. The city is located at $52^{\circ} 31^{\prime}$ ' $12^{\prime \prime}$ latitude and temporally very liberal generally, as regards e.g. opening hours of shops and pubs, and in terms of lighting: While the lighting concept

1 In analogy to landscapes, i.e. the visible features of an area of land [14], lightscapes can be defined as the sum and spatial arrangement of the visible lights in a given area. 
[15] formulates recommendations, there is no hard regulation governing when the use of artificial illumination is permissible. With the exception of individual cases in which time caps have been established via ordinances following conflict [see e.g. 16], schedules can be determined freely. All three areas also share that they are centrally located, high-density, mixed-use (including: housing, offices, retail, gastronomy, entertainment) hotspots of day- and nighttime activity [17]. They differ, however, in terms of their built structure and overall brightness. Alexanderplatz and Potsdamer Platz are typical examples of highly symbolic and representative city centres: They feature large-scale landmark buildings - albeit from different eras ${ }^{2}$ - and are among the brightest spots in Berlin, as became evident in an aerial survey of the city's upward light emissions [18] (fig. 1). Hackescher Markt, by contrast, is, with its five-story block buildings from the late $19^{\text {th }} /$ early $20^{\text {th }}$ centuries, considerably more mundane in its built structure and appears far less bright in the aerial survey.

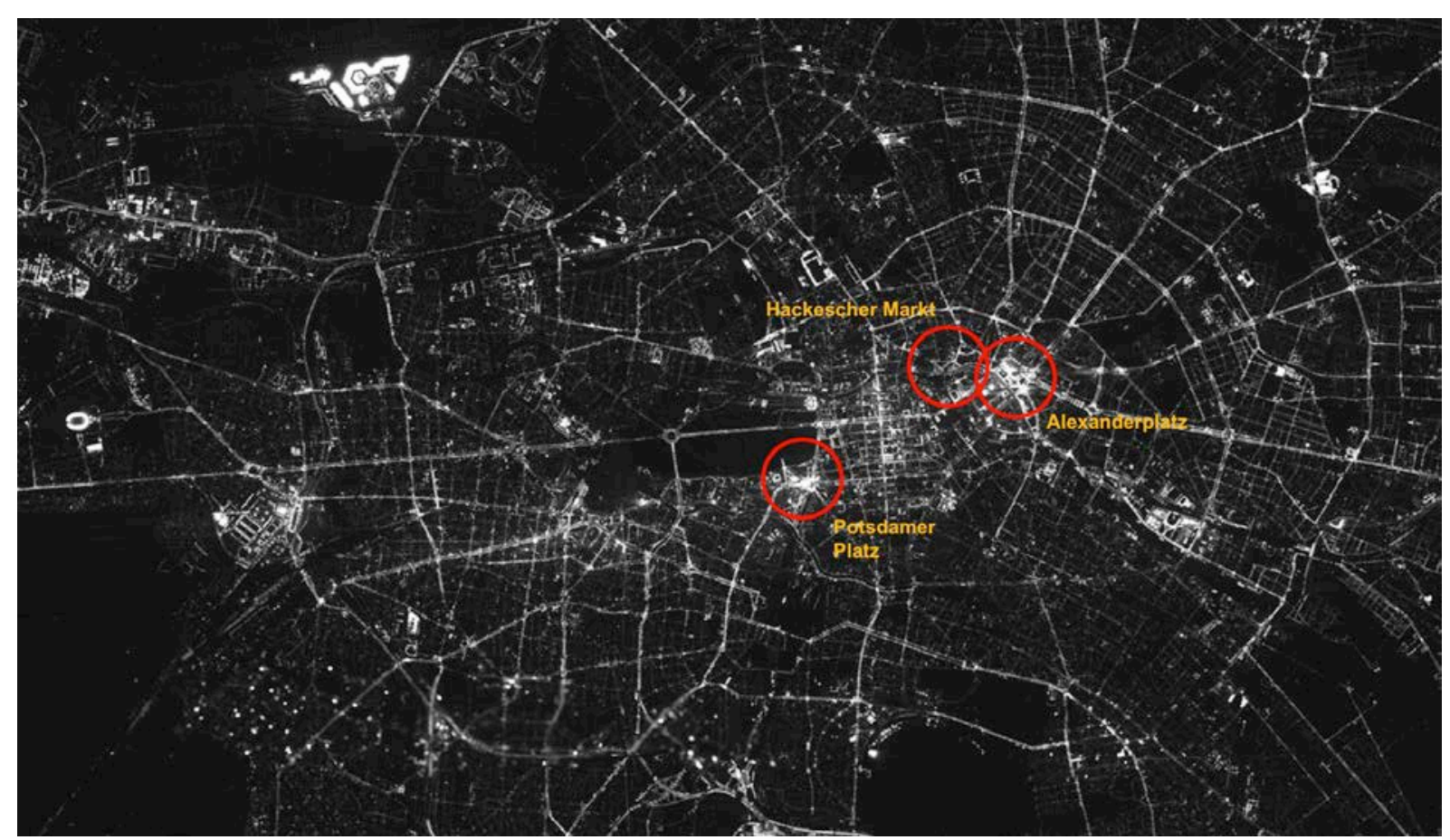

Fig. 1: Aerial image of Berlin by night [18; cropped] and locations of case study areas (own addition)

\subsection{Data Collection: Generating the Time Lapse Videos}

Data is gathered via series of photos that are assembled into time lapse videos. Prior to the night(s) of documentation, several parameters must be determined that will affect the possibilities and limitations of the study as a whole. The objectives are (1) to capture the lights of the relevant area and their on/off patterns as completely and precisely as feasible, and (2) to facilitate multiple usage of the images for complimentary analyses downstream, e.g. of the lights' brightness. Taking test photographs in advance is highly recommended, as this provides valuable orientation for decisions regarding the camera's perspective, setup and settings.

Perspective: The camera's vantage point should remain fixed throughout the recordings. It determines which lights are visible in the images and which aren't, and thus which elements can or cannot be included in the analysis. A perspective should be chosen from which a maximum of the area's lights is in the camera's field of vision - ideally an elevated location at the edge of the target area (here, the upper storeys of tall buildings were used - fig. 7-9). Exposure to stray light should be minimised to prevent veiling/blooming effects. To cover the lightscape more completely, multiple cameras can be installed from complementary perspectives.

Recording date(s): Nights can be documented individually, as done here, or in series, as in [12]. In either case, the choice of date(s) is crucial for comparisons among areas and nights, as lighting schedules are likely to change seasonally, with shifts in sunset and sunrise times, as well as during the week, especially between weekand weekend-nights [12]. If several locations are to be compared, they will thus ideally all be recorded on the same night(s). If this is not feasible, as was the case here (table 1), the parameters should be kept as similar as possible.

${ }^{2}$ Alexanderplatz with its landmark TV tower is the showpiece centre of former East Berlin; Potsdamer Platz with its glitzy high-rise architecture is the result of a prominent reunification redevelopment project at the former border strip. 
Table 1. Berlin recordings: basic parameters

\begin{tabular}{lccc}
\hline & Alexanderplatz & Potsdamer Platz & Hackescher Markt \\
\hline Recording date & Tue, 18./19. June 2013 & Tue, 1./2. July 2014 & Tue, 24./25. June 2014 \\
\hline Sunset/sunrise time & 21:33 / 04:43 & 21:33 / 04:48 & 21:34 / 04:44 \\
\hline Recording time & $21: 30-04: 30$ & $19: 30-06: 00$ & $19: 30-06: 00$ \\
\hline & & All Areas & ISO: auto \\
\hline Camera & & Canon EOS 600D & White balance: auto \\
\hline Settings & Format: RAW & Aperture: f/3.5 \\
\hline Photography \& processing & Focus: fixed & FilouBerlin, Philipp Elgert and Franziska Ottrembka \\
\hline
\end{tabular}

Recording time: The recording time affects how extensively changes to the lightscape are captured. To document them to the fullest possible extent, recordings should reach from before the bulk of the lights come on until after they go off, which likely means beginning before dusk and ending after dawn. Precursory observations can help determine suitable points in time. Here, the pilot study at Alexanderplatz showed that it would be necessary to begin well before sunset and end after sunrise to capture most switch-ons and -offs. This was adopted for the two following cases (table 1).

Frame rate: The frame rate, i.e. the time interval between images, essentially determines how exact the temporal analysis can be. Shorter intervals allow for temporally more detailed analyses, but produce more data overall, and vice versa for longer intervals. Here, 1 frame was recorded per 30 seconds.

Camera hardware and setup: A standard digital single-lens reflex (DSLR) camera is fully sufficient for conducting the recordings. The camera can be set up temporarily and overseen personally, as done here, or installed fixedly for longer-term recordings. The camera should be protected against wind or tremors in order to avoid shifts in perspective. It is crucial that the camera's internal clock is correctly calibrated before the recordings begin, that sufficient power is available for the entire recording time, and that the automatic releaser is set to the desired frame rate.

Camera settings: The camera settings will affect the photographs' quality, comparability and usability for further analyses. Generally, images should be taken in RAW format to preserve maximum information, with focus and aperture fixed. To account for changing natural light conditions, white balance and either ISO or shutter speed are set to automatic. Both options have drawbacks in low-light situations: image readability can be impacted by high ISO (noise) or by slow shutter speeds (blur). The decision will especially depend on the desired outcome and the given circumstances (lightscape, camera). Here, auto-ISO and fixed shutter speed were chosen to avoid blurring of moving lights (advertisements, headlights); noise levels remained unproblematic for the analysis.

Quality control: The results of the recordings should be checked for plausibility: Do the times of the first and last images correspond to the beginning and end time of the recording? Is the total number of images feasible in relation to the overall recording time and chosen interval?

Time stamps: The individual images are time-stamped to facilitate manual sampling. The stamps' interval will affect the level of detail at which temporal data can easily be extracted. Each image can be marked with its time of recording, which allows for quick pinpointing of the exact time of changes in the video without reverting to the individual photographs. However, the time stamps will not be readable in the running video. Additionally or alternatively, larger time segments are used that reflect the planned sampling rate, as done here with 15-minute sections.

Assembly: The time lapse video is assembled from the individual images by using video editing software (here: Adobe Premier Pro, also used for placing the time stamps; fig. 2). Downsampled versions facilitate online publishing, and thus further inquiry by others ${ }^{3}$.

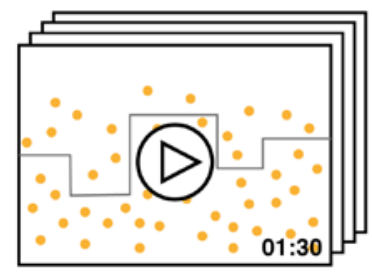

Fig. 2: Assembly of time lapse video 


\subsection{Data Extraction and Sampling: Reading the Time Lapse Videos}

The objective here is to identify the data in the images that is relevant to the study, and to form categories of lighting who's on/off-times will later be compared. In the interest of accessibility, a low-tech, manual approach is adopted for data extraction, notwithstanding that software-based solutions are possible and bring advantages in terms of scalability.

(De)Selection of lights: The images will typically contain lights that are beyond the scope of the study and are therefore excluded from the analysis. This especially concerns lights further afield that do not belong to the area in question (fig. 3A). Further categories of lights can be deselected according to the study's aims by defining additional criteria of exclusion. Here, lights that are not part of the physical urban structure and/or whose temporality are not typically addressed via public regulations were excluded (esp. vehicle headlights and user-controlled indoor lights shining out through regular apartment/office windows). Additionally, in the interest of manageability, very small lights were disregarded.
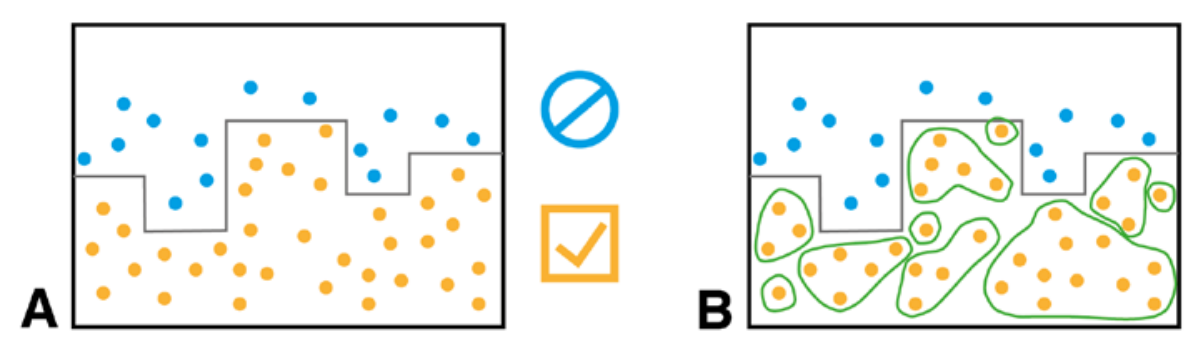

Fig. 3: A: (De)Selection of lights, B: Identification of temporal units

Identification of temporal units: The selected lights are those that the study will be based on. These need to be identified and characterised. Given that the focus of the study is the lights' temporality, they are counted not individually as light points, but as temporal units of lighting. What defines a temporal unit is that it is, in all likelihood, operated via one switch. It can thus consist of one single light or of multiple interconnected light sources (fig. 3B). Temporal units are identified by repeated observation of the videos, consideration of the individual images, and logical inference: Which lights come on/go off at the same moment? And which can be assumed to belong together? Each unit is distinctly named and entered into a database - here, a spread sheet was used (fig. 4).

Classification of units: The classification of units according to selected characteristics is central to the following comparative analysis: it determines the categories of lighting whose temporalities are contrasted. Which characteristics are chosen for the classification will depend on the research interest at hand. Here, the aim was to investigate whether temporal lighting practices differ a) amongst the three areas and b) amongst the purposes for which the lights are used. The units were therefore classified according to their locations and according to the following functional types:

- $\quad$ infrastructural lighting, i.e. basic illumination that serves to establish visibility for traffic safety and the use of public spaces at night, including public transport stations (e.g. bus stops, railway platforms);

- $\quad$ architectural illumination, i.e. lighting used to stage buildings (e.g. facade lighting);

- commercial lighting, i.e. illumination used for advertisement purposes, such as neon signs or shop window lighting;

- $\quad$ indoor lighting, i.e. light that is used for indoor functions such as fulfilling tasks in shops, which is hardly intended to shine outdoors but escapes through glass elements.

Additionally, particularly conspicuous lighting units with a perceived strong influence on the lightscapes were earmarked for individual consideration. Further options of classification include: types of operators (e.g. public/private), size or brightness levels of units.

Sampling of temporal data: The sampling rate at which the lights' on/off-times are extracted determines the level of detail at which their temporalities are studied. Possibilities range from the threshold set by the frame rate to larger intervals. By orienting the sampling rate on the temporal density of on/off-changes visible in the videos, high data volume and effort can be balanced against critical loss of data. Here, 15-minute segments were used. The on/off times of each unit can be identified manually by repeatedly watching the videos (as done here), or via automation [as in 12]. The on/off times are entered into the database for each unit by indicating its status per time segment of each night (fig. 4). 


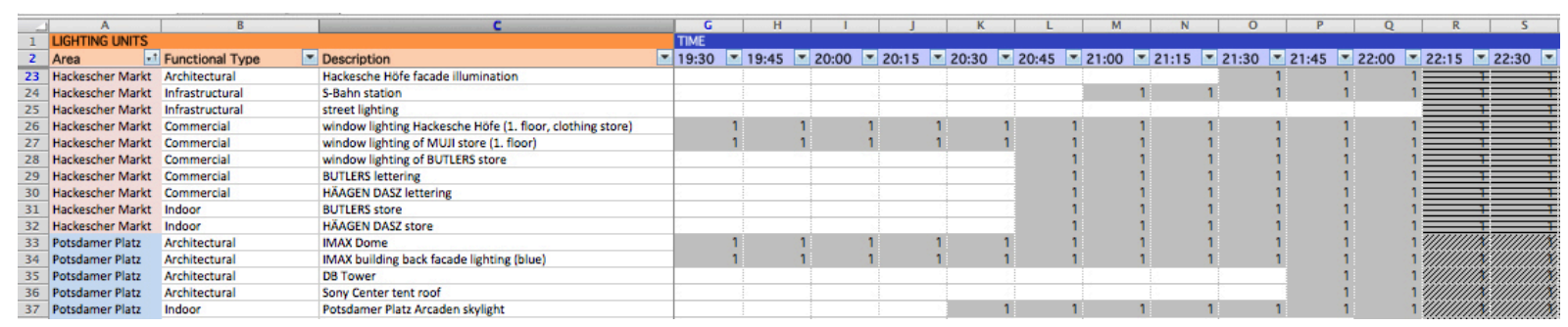

Fig. 4: Screenshot of spread sheet used for classification of units and sampling of temporal data (excerpt; "1" indicates the unit is "on”)

\subsection{Data Analysis: Determining and Comparing Temporal Profiles}

The primary aim of the analysis is to describe and compare the temporalities of different categories of lighting. To this end, on/off data of the units is first aggregated for each category of classification, to then systematically contrast these regarding their temporal characteristics. Visualisations are used throughout the analytical process to aid the identification of patterns, similarities and differences.

Individual temporal profiles: The time series of on/off data extracted from the videos for each lighting unit constitute the units' individual temporal profiles. These are the base elements of the analysis. The individual temporal profiles can be visualised as bar diagrams that plot their on/off state against the sampling times (e.g. in a spreadsheet - fig. 4). Stacking and (re-)sorting the individual bars according to categories of classification or characteristics of the temporal profiles provides first impressions of temporal correlations. This allows for reviewing how meaningful the chosen categories of classification are and can provide pointers for their readjustment and for further avenues of inquiry.

Aggregate temporal profiles: To study the behaviour of different categories of lighting, aggregate temporal profiles are formed. These are time series of on-rates, which are calculated for each time interval by determining the percentage of units that is illuminated within one category of classification. Loss of relevant data can occur through this aggregation, especially if units' changes cancel each other out by switching in opposite directions within one time segment: This should be reflected in the analysis, or, if it occurs frequently, it may be appropriate to increase the sampling rate. The aggregate temporal profiles are visualised as on-curves by plotting on-rates against time in line charts. By combining in one graph the on-curves of different categories of lighting, similarities and differences quickly become apparent (e.g. fig. 11).

Phases of illumination: The central concept for describing and comparing the aggregate temporal profiles is to consider the evolution of lighting behaviour over time in terms of phases of illumination. These are deduced from the on-curves by differentiating time segments during which the development of on-rates corresponds to the following basic modes (table 2):

Table 2. Differentiation of phases of illumination

\begin{tabular}{|c|c|}
\hline Types of phases & Development of on-rate \\
\hline Dynamic & the on-rate changes in close sequence \\
\hline - $\quad$ Increase & - Units successively come on \\
\hline - $\quad$ Decrease & - $\quad$ Units successively go off \\
\hline - $\quad$ Diffuse & - $\quad$ Units come on and go off in a dispersed manner \\
\hline Static & there is no or marginal change in on-rate \\
\hline - $\quad$ Full-on illumination & - $\quad$ All units are on: $100 \%$ on-rate \\
\hline - $\quad$ Part-on illumination & - $\quad$ Some units are on: $1-99 \%$ on-rate \\
\hline - Full-off illumination & - $\quad$ All units are off: $0 \%$ on-rate \\
\hline
\end{tabular}

Different types of aggregate lighting practices can now be grasped in temporal terms by reading from the on-curves each phase's respective

- $\quad$ timing, i.e. the points in time when it begins and ends, and

- $\quad$ duration, i.e. the period of time from beginning to end.

Temporal profiles can differ in terms of the number, types and sequences of phases they are composed of, and in the timing and duration of these phases - ranging from one phase that extends throughout the night (e.g. if a group's units are all illuminated from start to end), to series of multiple different phases. Bar diagrams that visualise each phase's timing and duration in conjunction with the on-curves they are derived from facilitate 
comparisons, and simultaneously make transparent the underlying interpretations regarding the phases' type, beginning and end (e.g. fig. 11).

Overall characteristics: At a more general level, the aggregate temporal profiles can be further characterised in terms of their:

- $\quad$ dynamics, i.e. the amount of change they exhibit over time. These differences become visible in the on-curves, which can be more 'flat' or 'mountainous', indicating stronger stability or pronounced dynamics, respectively (fig. 5A).

- temporal extension, i.e. the proportion of units that are illuminated in relation to the amount of time during which they are illuminated. High on-rates for extended periods of time indicate high temporal extension and v.v. (fig. 5B).

- $\quad$ strength, i.e. how characteristic the behaviour is that they represent. The more uniform the temporal profiles of the (categories of) units that compose them, the stronger the aggregate temporal profile (fig. 5C).

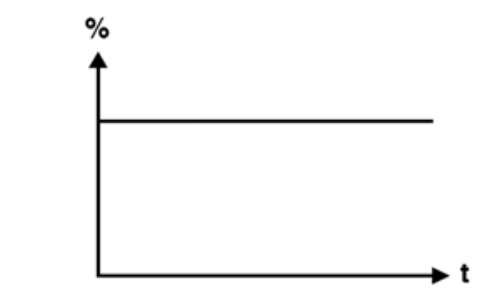

A

Stable temporal profile

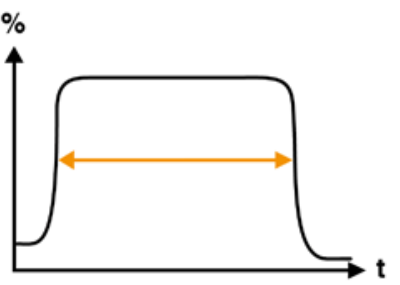

B

High temporal extension

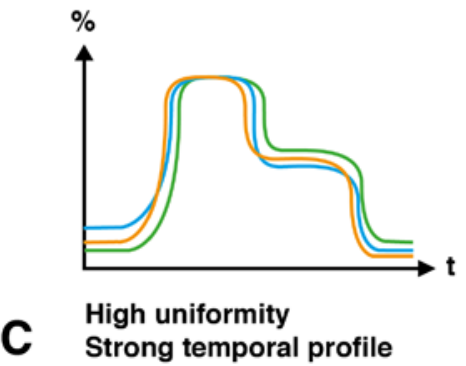

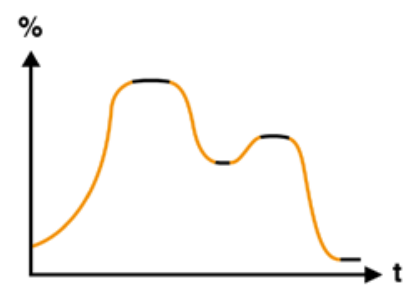

vs.
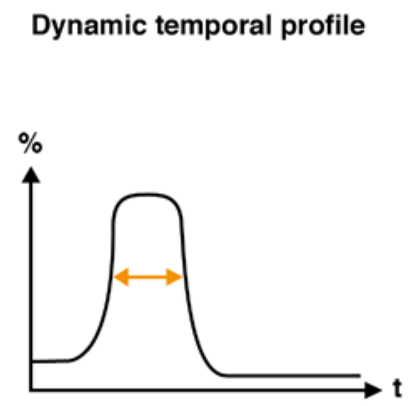

vs.

Low temporal extension

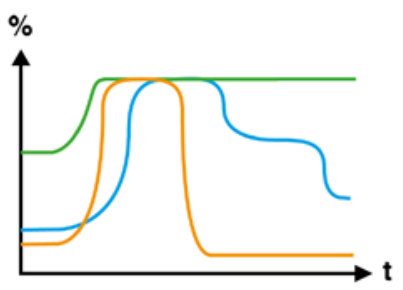

vs. Low uniformity Weak temporal profile

Fig. 5: Characteristics of temporal profiles

\section{$3 \quad$ Findings}

The comparative temporal analysis of the three urban centres' lighting moves from the general to the specific. First, the distribution of the identified lighting units across the categories of classification is contrasted to understand how these groups are structured. The phases of illumination of all units combined then provide a common reference point for the following comparisons: Each area's aggregate temporal profile is first contrasted against those of the other two, and then broken down into the functional types of lighting to compare their temporal profiles among each other. The same procedure is followed vice versa for the four types of lighting. By thus systematically intersecting the two forms of classification - area and type - with each other, the strength of each category's temporal profile is tested. In this way, first tentative indications can be gained of whether the lights' locations or their functions are more meaningful for the observed temporal practices. 


\subsection{Distribution of lighting units}

42 units were identified overall, 20 of which belong to Alexanderplatz, making it the most differentiated of the three lightscapes (fig. 6A). The areas' quantitative compositions in terms of functional types of lighting are roughly similar, with a proportional dominance of architectural and/or commercial units. While Alexanderplatz and Potsdamer Platz are nearly identical, Hackescher Markt stands out with its high proportion of commercial units. Among the types of lighting, commercial is dominant with 17 units, followed by architectural with 12 (fig. 6B). The different types are distributed similarly across the areas. Architectural units are the exception: over half are at Alexanderplatz, and only one at Hackescher Markt.

\section{Composition of the 3 Areas}

A

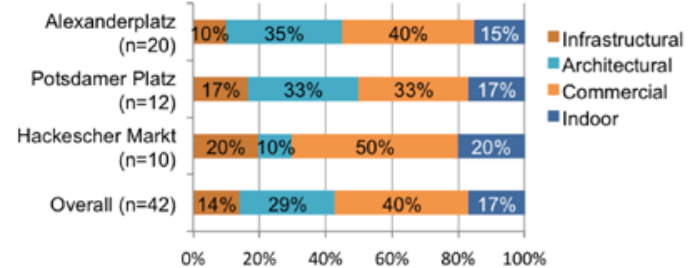

\section{Distribution of the 4 Types of Lighting}

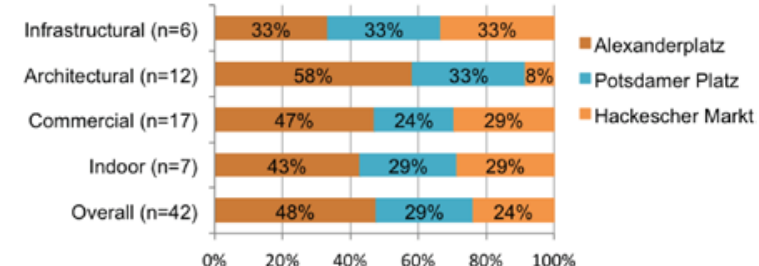

Fig. 6: Distribution of lighting units

The video stills provide a comparative impression of each lightscape during phases of full-on illumination (at 23:00) and part-on illumination (at 3:00). Conspicuous units are named in the captions (fig. 7-9).

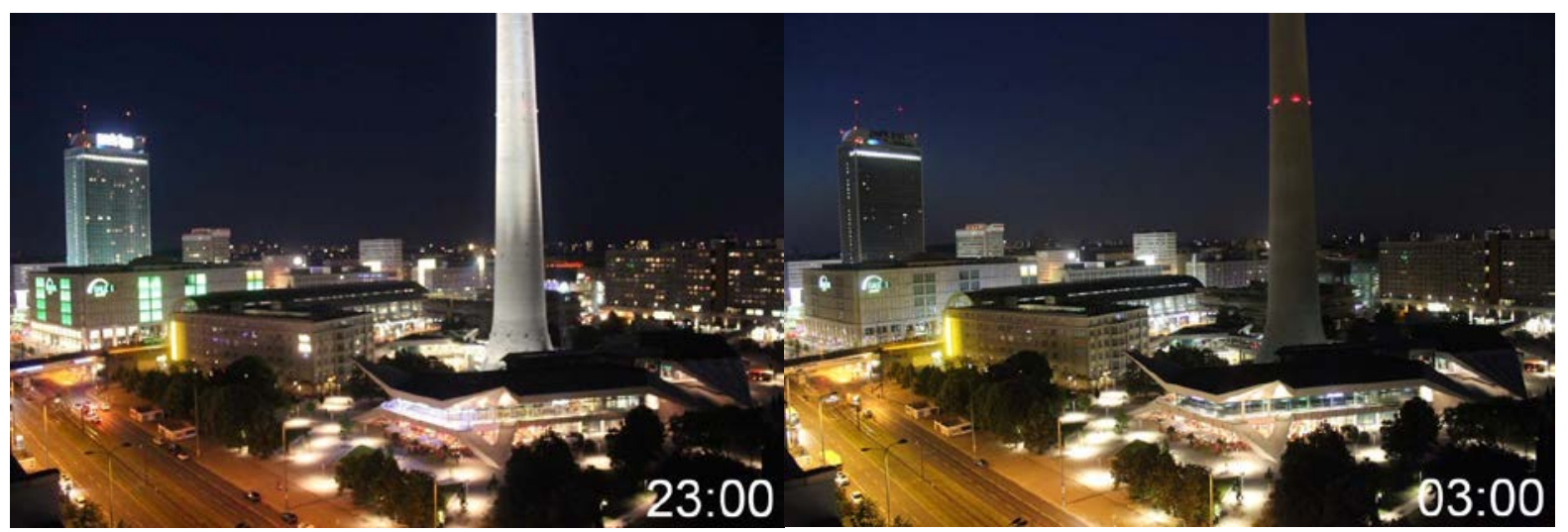

Fig. 7: Alexanderplatz. Conspicuous lighting units: in the foreground, the TV tower with its illuminated shaft, base and pedestrian area; in the background, the illuminated Park Inn hotel high-rise with its rooftop lettering, and the green facade elements and logos of the Galeria Kaufhof department store. On a smaller scale in the midground: the yellow Commerzbank sign, the horizontal advertisement banners on the elevated train tracks, and the clothing store C\&A's rotating rooftop sign.

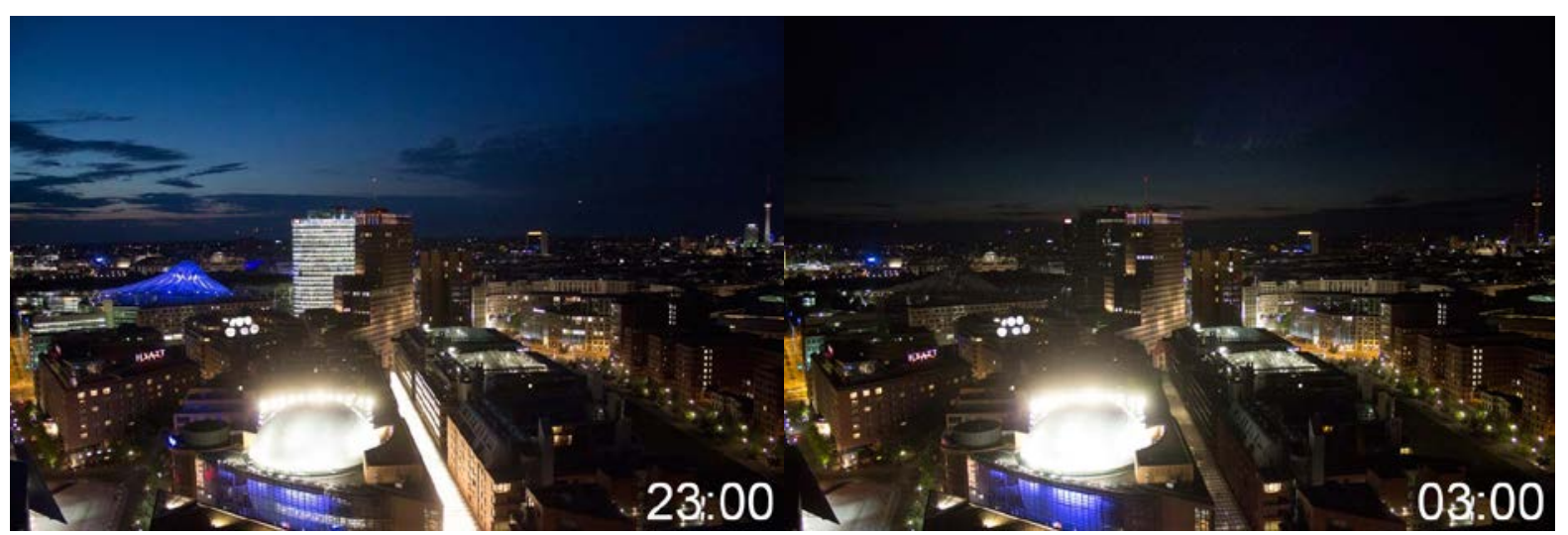

Fig. 8: Potsdamer Platz. Conspicuous lighting units: in the foreground, the brightly illuminated dome of the IMAX cinema and the strip of roof lights of the Potsdamer Platz Arcaden shopping centre; in the background, the glass Bahn-Tower and the colour-changing tent roof of the Sony Center. On a smaller scale in the midground: illuminated rooftop satellite dishes. 


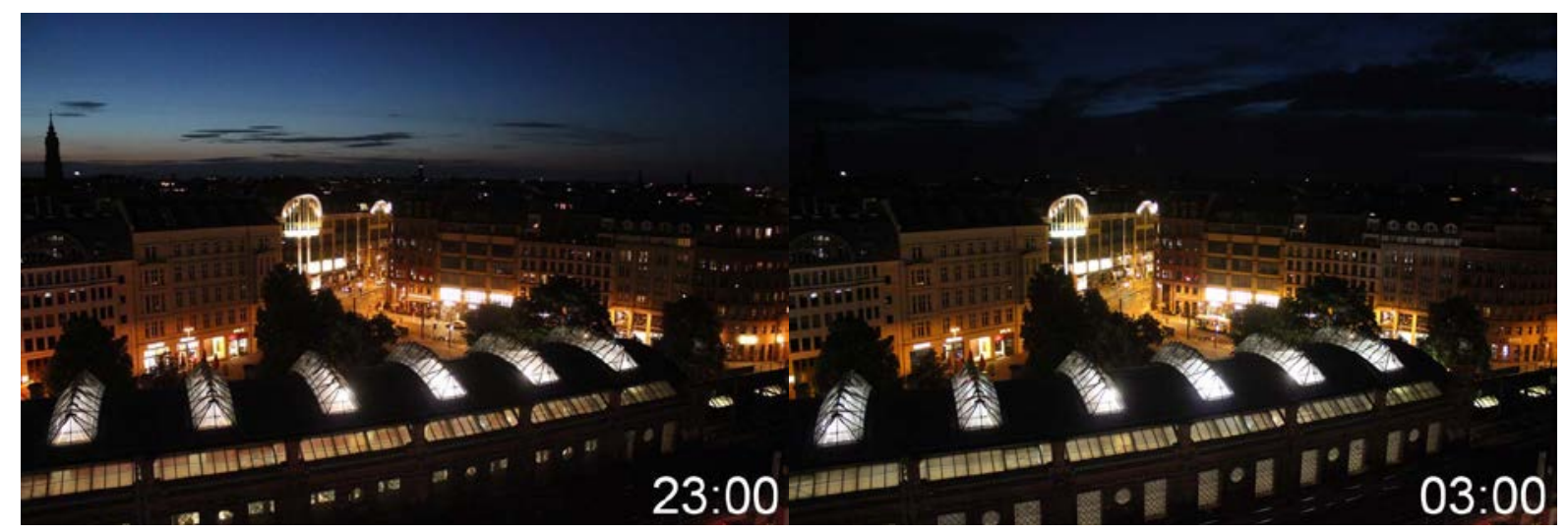

Fig. 9: Hackescher Markt. Conspicuous lighting units: in the foreground, the light rail (S-Bahn) station with its platform lighting shining out through glass elements; in the midground, the illuminated facade of the corner building at the central intersection and the band of lit shop windows that line the edge of the square and street.

\subsection{Overall Temporal Profile and Phases of Illumination}

The overall temporal profile of the three case study areas was calculated by combining the data of all observed units ${ }^{4}$. The corresponding overall on-curve exhibits a sequence of five phases (fig. 10):

- $\quad$ Phase 1 - Dynamic: Increase. Starting from an initial on-rate of $18 \%$, units come alight as night falls until full illumination is reached at ca. 22:15.

- $\quad$ Phase 2 - Stable: Full-on illumination. All units are on and remain so until around midnight.

- $\quad$ Phase 3 - Dynamic: Decrease. In the following two hours, about $1 / 3$ of the units are switched off.

- $\quad$ Phase 4 -Stable: Part-on illumination. The units that are still on remain lit with little change until around 4:15.

- $\quad$ Phase 5 - Dynamic: Decrease. Lights are successively switched off down to an on-rate of $27 \%$ as daytime arrives.

This overall pattern provides comparative cornerstones with which the various temporal profiles are contrasted.

\section{All Units across All Areas: On-Curve with On-Rates and Phases}

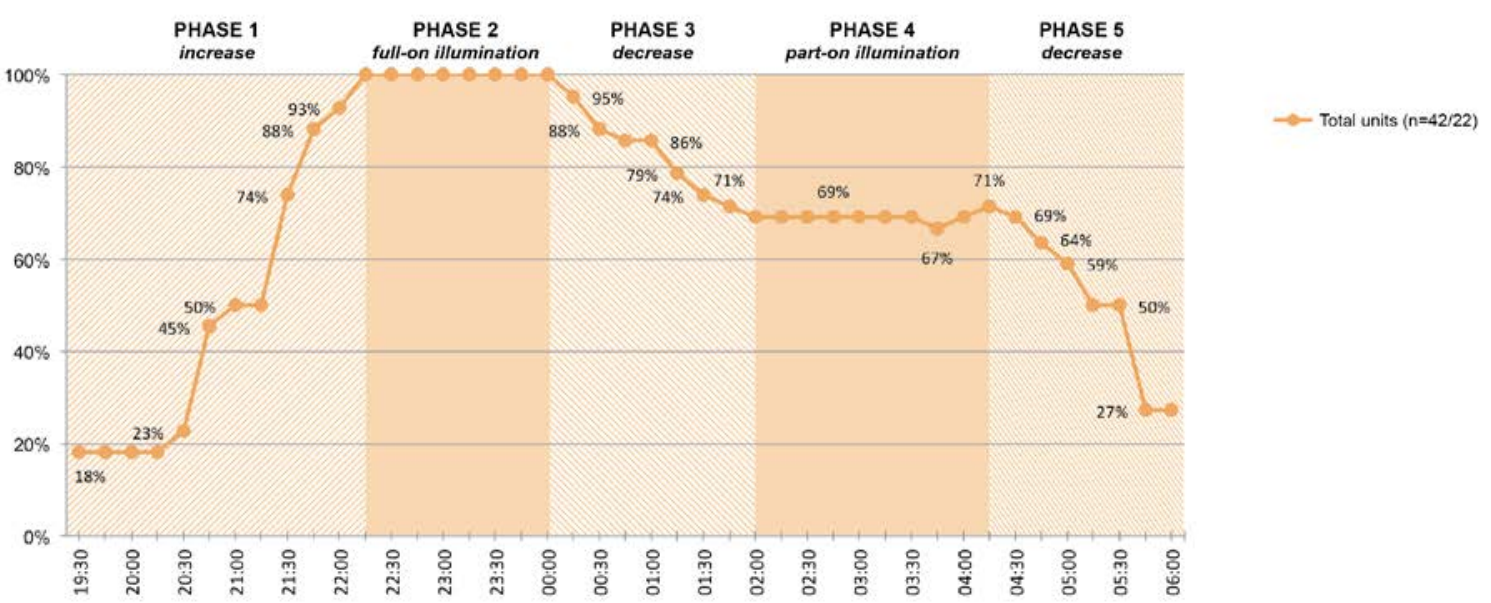

Fig. 10: Overall on-curve. The two numbers for the basic population (n) indicate the overall total for all three areas and the total without Alexanderplatz.

\footnotetext{
${ }^{4}$ The shorter recording time at Alexanderplatz was accounted for here and in the calculation of on-rates for the functional types of lighting across the three areas by adapting the potential maximum number of illuminated units to include only those in the other two areas before the beginning and after the end of the Alexanderplatz-recording.
} 
All Areas: On-Rates and Phases
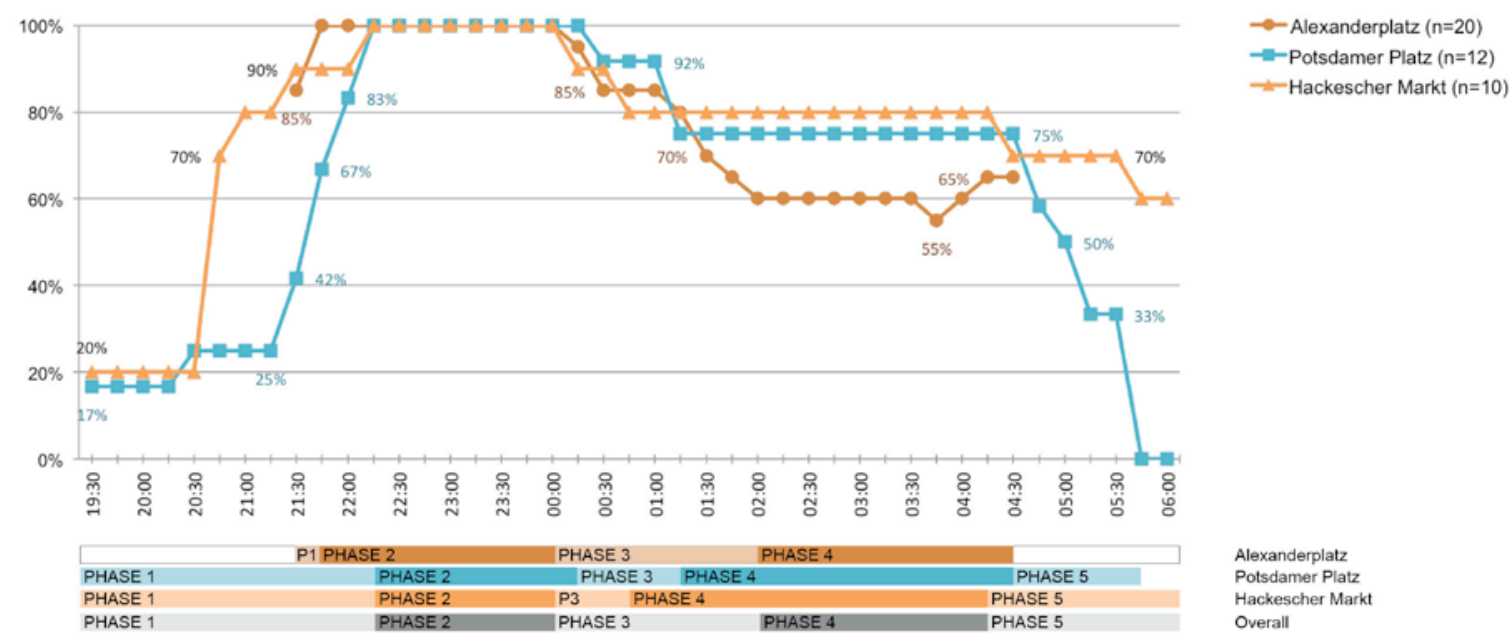

Fig. 11: On-curves with on-rates and phases of the 3 areas

\subsubsection{Alexanderplatz}

Alexanderplatz stands out among the three areas through its extended phase 2, which begins comparatively early $^{5}$, and especially through its extended phase 3 : at close to two hours, it is generously twice as long as at Potsdamer Platz, and three times as long as at Hackescher Markt (fig. 11). Alexanderplatz' lightscape is particularly dynamic: After midnight, hardly an hour - only that between 2:00-3:00 - goes by without units being switched off or back on, effectively blurring the edges between phases 3, 4 and 5 . The fact that select units are switched back on in the early morning hours is unique to Alexanderplatz. Alexanderplatz also stands out as the lightscape that reaches the lowest on-rate in phase 4.

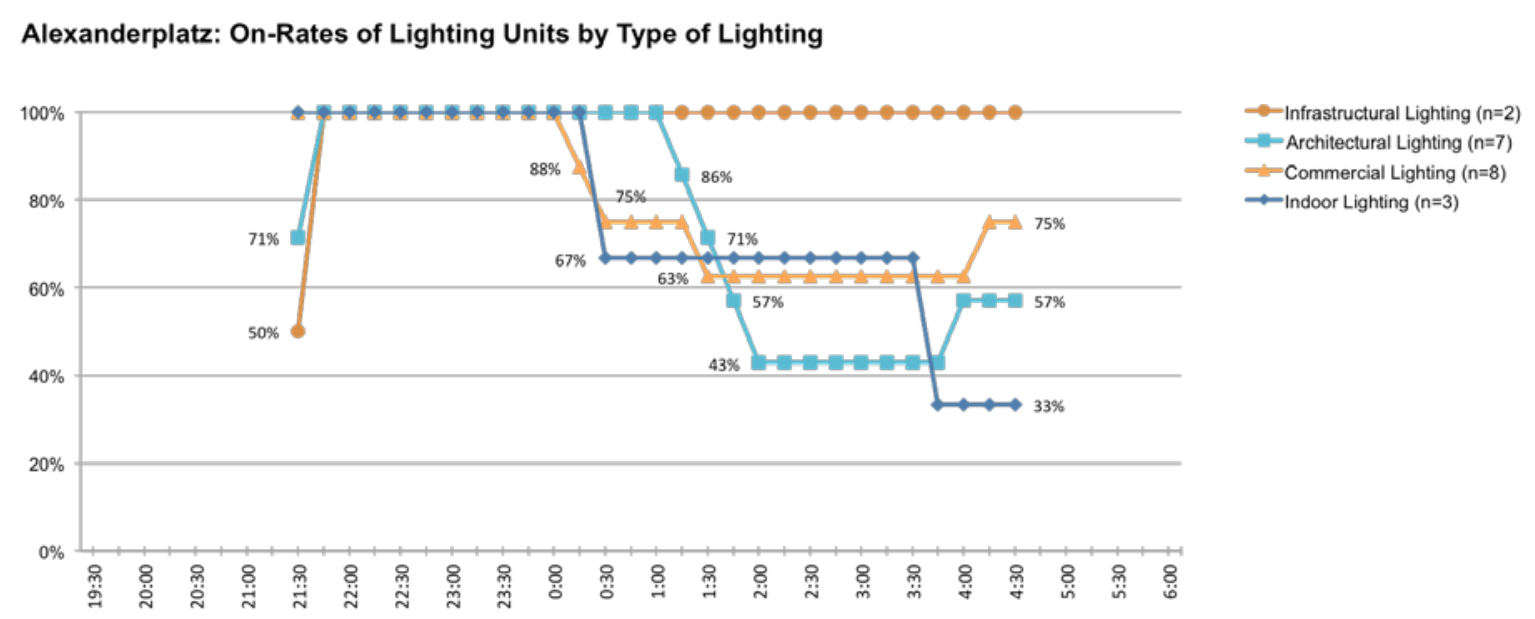

Fig. 12: Alexanderplatz on-curves

The curves of the different functional types of lighting evolve similarly before, but quite heterogeneously after midnight (fig. 12). The types differ in terms of whether or not they are partially switched off, and those which are exhibit considerably different modes of reduction in terms of timing and speed, leading to the high temporal extension of phase 3 . The extent to which lights are switched off also differs significantly: While infrastructural lighting remains fully on, about $1 / 3$ of the commercial and indoor units and over half of the architectural units are switched off. Each of these three categories contains at least one intermittent unit that is relit (fig. 13). With one clear exception (the lettering atop the Park Inn Hotel, which goes off around when two

5 Though Alexanderplatz was recorded ca. 2 weeks before the other two areas (mid-June vs. end June/beg July), this cannot account for the fact that full-on illumination is reached ca. half an hour earlier, as the sun sets at nearly the same time. 
others are relit), these are switched off within the hour after midnight, remain off for ca. 2,5 hours, and come back on at around 3:00 or 4:00, respectively. Interestingly, there is a stark contrast in timing between two units of the same type (commercial lighting) and of similar character (illuminated advertisement).

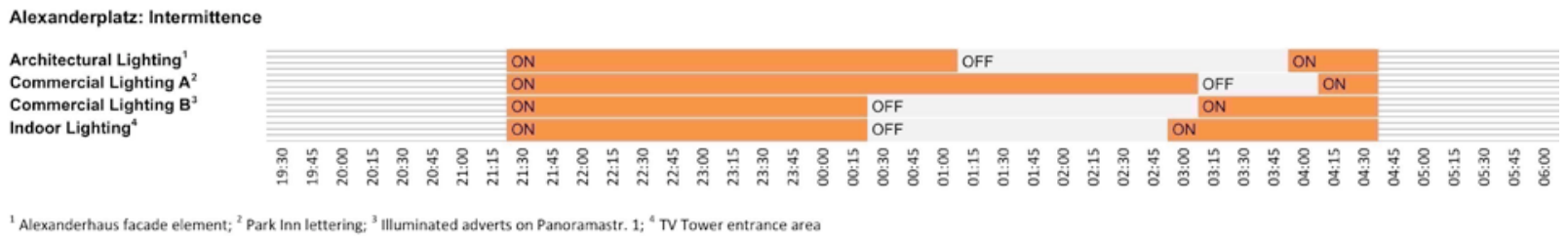

Fig. 13: Alexanderplatz: Temporal profiles of intermittent units

\subsubsection{Potsdamer Platz}

The timing and duration of the five phases at Potsdamer Platz roughly mark the middle ground among the three areas (fig. 11), with a slight bias toward stable phases 2 and 4. Its compact on-curve indicates its comparatively low temporal extension: the bulk of the units are switched on late and within a short time, and the remarkably quick and consequent switch-off process begins early. The changes that take place during the course of the night are fairly small and tightly clustered: it is a rather stable lightscape.

Potsdamer Platz: On-Rates of Lighting Units by Type of Lighting
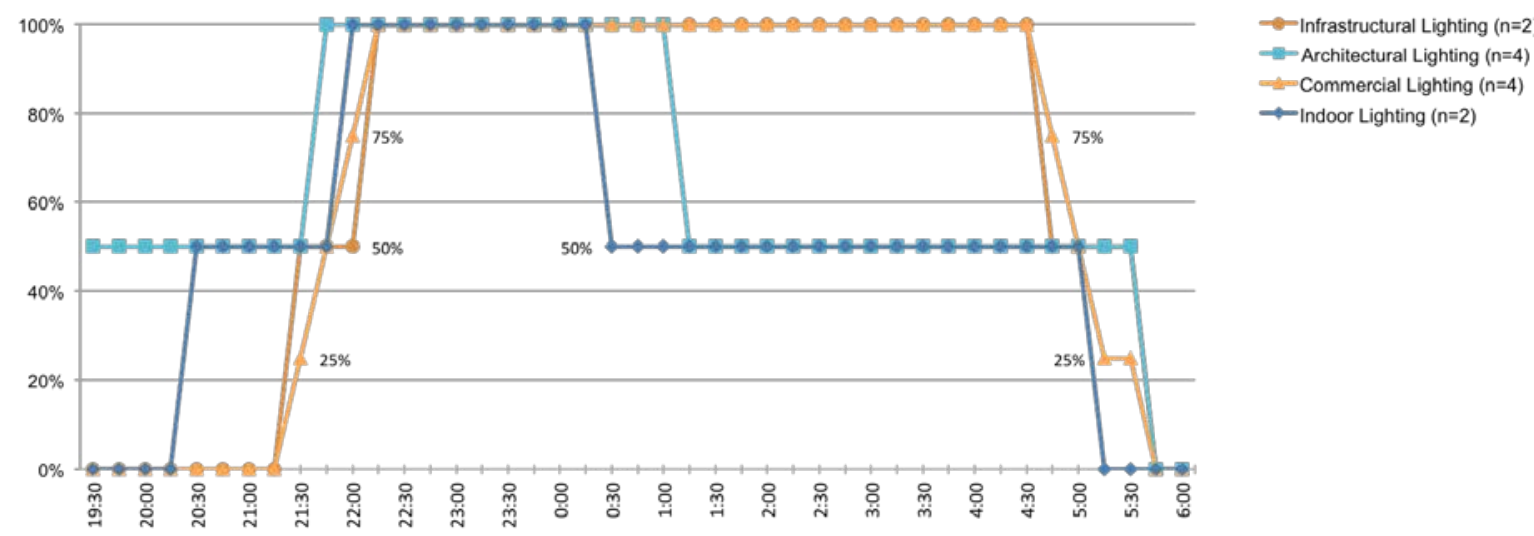

Fig. 14: Potsdamer Platz on-curves

The on-curves of the four types of lighting reveal two distinct groups of temporal profiles, set apart by whether or not they are partially switched off during the night, i.e. whether they skip phases 3 and 4 (fig. 14). Firstly, the curves of the area's infrastructural and commercial lighting are nearly identical and the area's most temporally extended and stable types, coming on at nearly the same time to remain on all night until they are rapidly switched off in the early morning. Secondly, the architectural and indoor units - accountable for Potsdamer Platz' reductions in phase 3 - are very similar, the main difference being that architectural lighting is somewhat more temporally extended.

\subsubsection{Hackescher Markt}

Hackescher Markt stands out with its particularly short dynamic phase 3 and long static phase 4 (fig. 11). The area's on-curve underscores this character of stability. Once all units have come on, the changes that occur are very limited: During phase 3, only $20 \%$ of the units are switched off, marking the lowest reduction among the three areas; even in phase 5 , only $20 \%$ are switched off, resulting in a high on-rate of $60 \%$ at the end of the recording, after daylight has returned. 
Hackescher Markt: On-Rates of Lighting Units by Type of Lighting
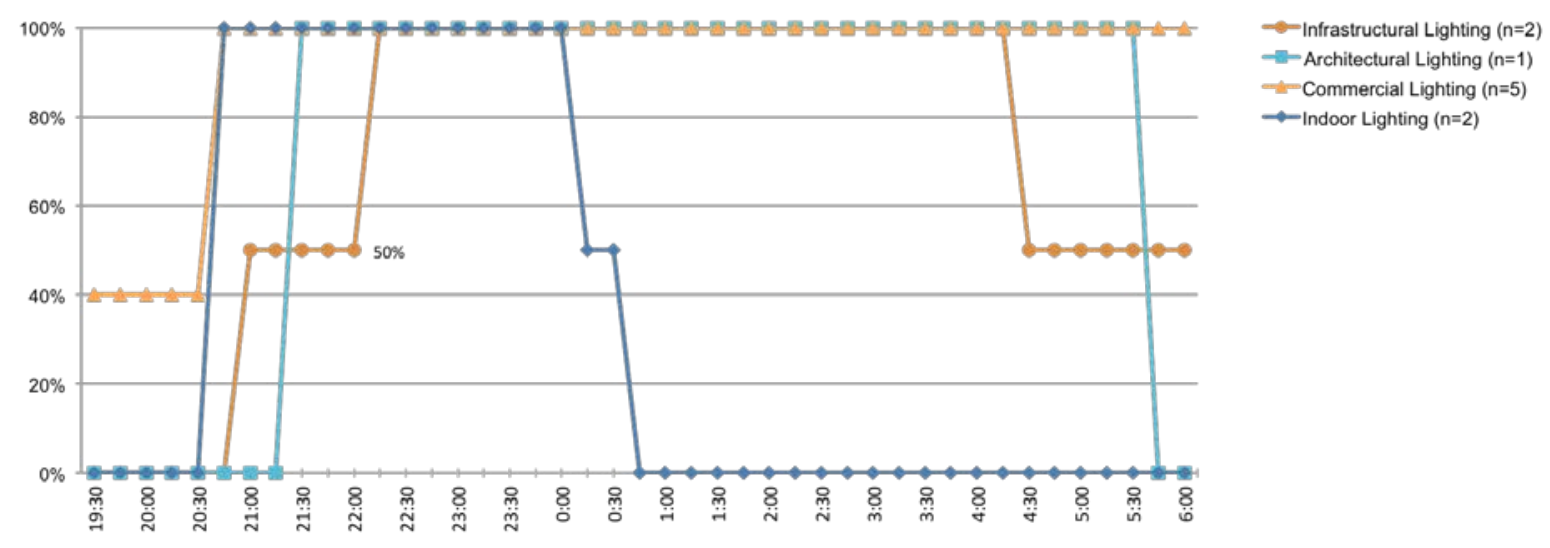

Fig. 15: Hackescher Markt on-curves

The temporal profiles of the types of lighting at Hackescher Markt share some characteristics and diverge in others (fig. 15). The starkest contrast exists between indoor lighting and the other three groups. Indoor lighting is the only type to be switched off during the night, i.e. it is exclusively accountable for the changes in phase 3 . All other types remain fully on until the morning, effectively skipping phases 3 and 4, and, in the case of commercial lighting, even phase 5. This is particularly remarkable as commercial lighting is the category with the highest number of units at Hackescher Markt. While commercial lighting is thus the most temporally extended type in this area, indoor lighting is clearly the least extended.

\subsubsection{Comparison between the Lightscapes}

The temporal profiles of the three areas share a similar basic pattern of change insofar as the five phases are recognisable in each. Beyond this fundamental similarity, however, considerable differences exist.

Alexanderplatz stands out as the most dynamic lightscape, with the lowest on-rate during the night (phase 4), as well as a high level of heterogeneity among the temporal profiles of the four types of lighting, resulting in a comparatively weak temporal profile. Hackescher Markt marks the opposite end of the spectrum: As three of four types of lighting are not reduced at all during the night, it features the highest on-rate and is not only the most stable, but also the most temporally extended. With its far-reaching stability in phases 2-4, high on-rate during phase 4, and considerable uniformity among the types of lighting, Potsdamer Platz shares several characteristics with Hackescher Markt, though these are not quite as pronounced. In contrast to Hackescher Markt, however, it is temporally less extended, notably reaching full-off before the end of the recording.

The contrasts in the temporal profiles of the types of lighting result in shifts in the composition of the lightscapes as the night progresses. Contrasts are especially pronounced at Potsdamer Platz, where commercial and architectural lighting each account for one-third of the illuminated units in phase 2, increasing to $44 \%$ respectively decreasing to one-fifth (22\%) in phase 4, and at Hackescher Markt, where commercial lighting increases from half to nearly two-thirds (63\%) from phases 2 to 4, while indoor lighting drops from one-fifth to zero. While the extent of these shifts is similar in numeric terms, their visual effect is not: They are hardly perceptible at Hackescher Markt, as the extinguished indoor units are comparatively small, but clearly visible at Alexanderplatz, where defining architectural units are switched off (fig. 7). Architectural lighting at Potsdamer Platz also exemplifies how strongly the individual temporal profiles of otherwise similar units can contrast: while the landmark DB Tower and Sony Center are among the area's temporally least extended units (on for ca. 3:15 hours) and switched off by 1:00, the illuminated dome of the IMAX cinema, which is hardly visible from street level, remains on until the early morning (ca. 10 hours). 
Types of Lighting across All Areas: On-Rates and Phases
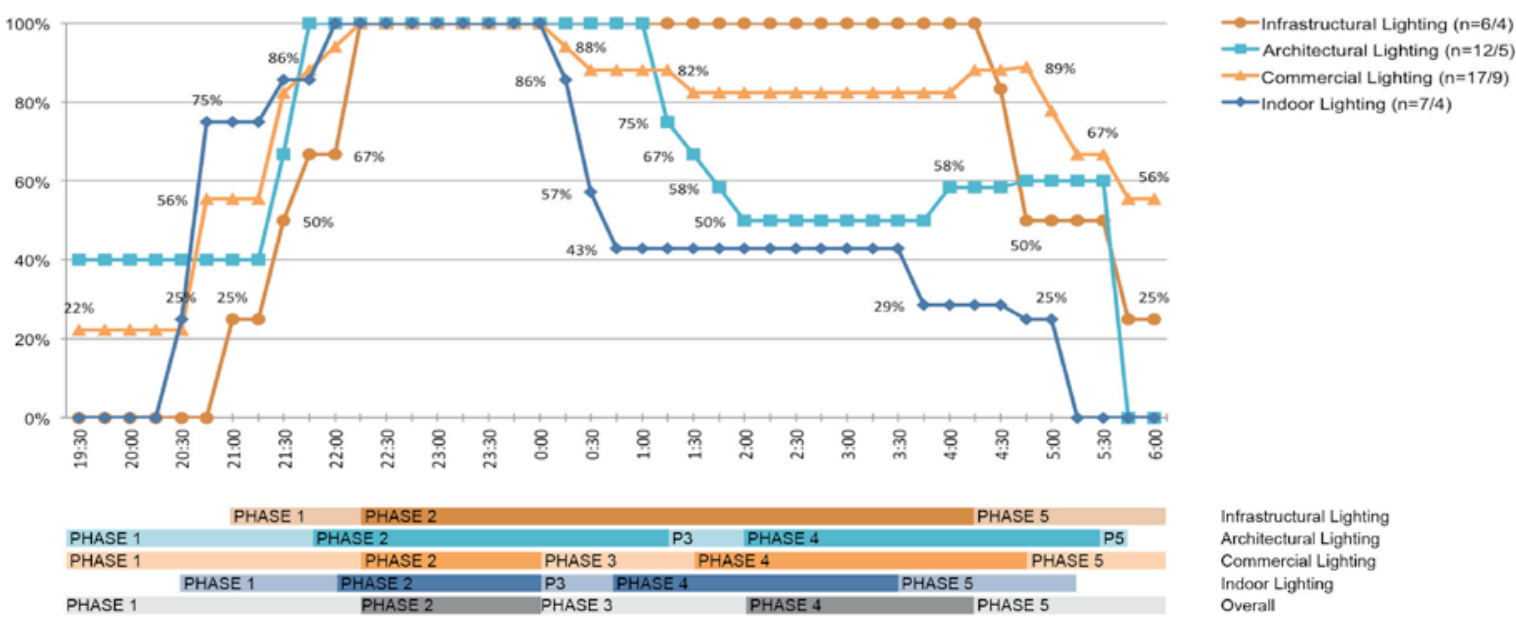

Fig. 16: On-curves with on-rates and phases of the types of lighting

\subsubsection{Infrastructural Lighting}

Infrastructural lighting stands out particularly through its very stable profile: It is switched on in the evening and stays fully on until it is switched off again in the morning, thereby skipping phases 3 and 4 (fig. 16). For that, its switching-on begins later than any other type, tying with commercial lighting as the last to enter phase 2, and switching off beings fairly early.

\section{Infrastructural Lighting: On-Rates of Lighting Units by Area}

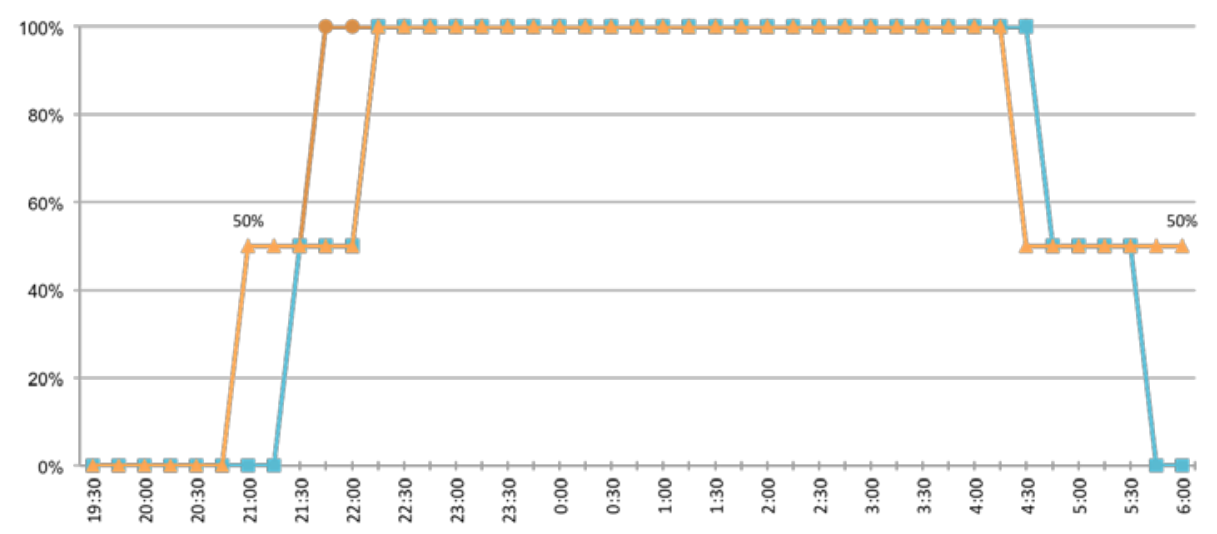

Fig. 17: Infrastructural on-curves

The infrastructural on-curves are very uniform across the three areas: divergences are small and limited to phases 1 and 5 (fig. 17). For 6 of the 10 recorded hours, the on-rates are identical. As such, infrastructural lighting has a very strong temporal profile.

\subsubsection{Architectural Lighting}

Architectural lighting is distinguished by extended stable phases on the one hand, and short, but intense dynamic phases on the other (fig. 16). In particular, phase 2 begins early and extends about one hour longer than either of the other two types that are partially switched off, and phase 4 stretches far into the morning hours. Despite the two phases of reduction being rather late and short, their switch-off rates are comparatively far-reaching: Half the units are off in phase 4, and the rest are extinguished completely before the end of the recordings. Conversely, at $40 \%$, the initial on-rate is high. 
Architectural Lighting: On-Rates of Lighting Units by Area
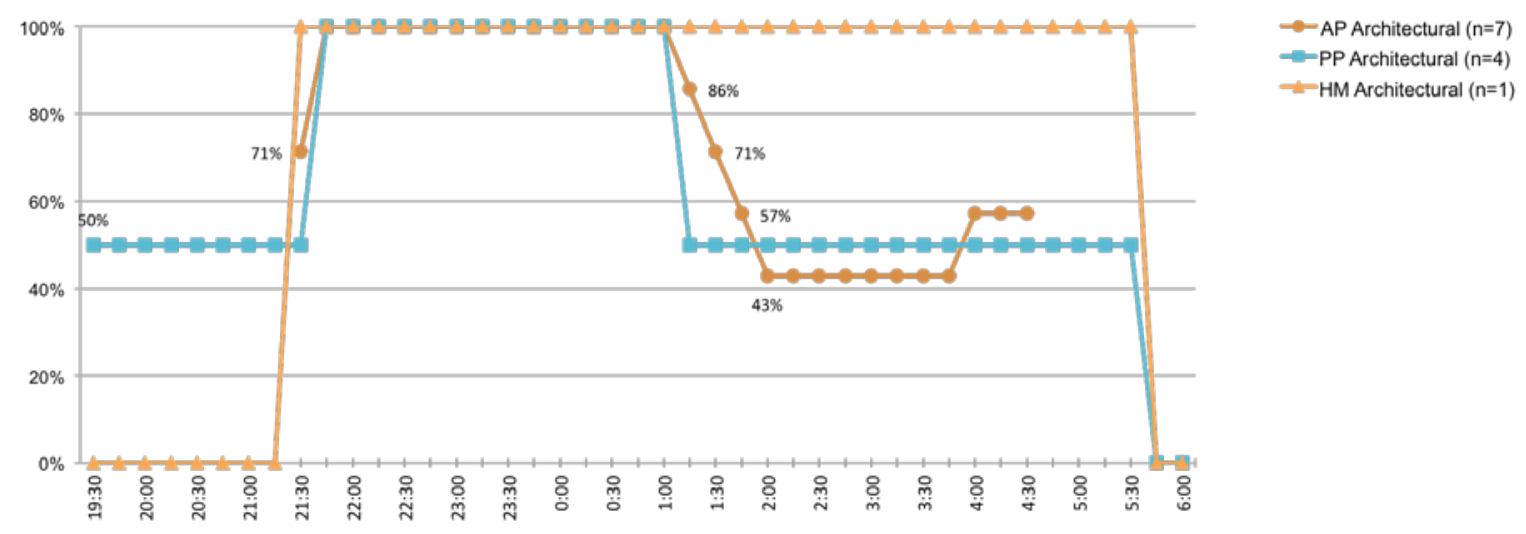

Fig. 18: Architectural on-curves

The three areas' architectural on-curves are rather similar, indicating a strong temporal profile (fig. 18). This is especially apparent for Alexanderplatz and Potsdamer Platz, which is where the bulk of the units (11 of 12) are located. Not only do their full-on phases and nighttime reductions begin at the same time, but their switch-off rates are also alike. While Potsdamer Platz sets itself apart through its high initial on-rate, Alexanderplatz does so with its intermittent unit that is relit at around 4:00. Hackescher Markt's curve seemingly contrasts, as its only architectural unit remains illuminated all night - however, so do half of the units in the other two areas.

\subsubsection{Commercial Lighting}

Commercial lighting stands out with its long dynamic phase 3 and its fairly short stable phase 2 (fig. 16). However, the changes it exhibits are actually quite small: Only a scant $20 \%$ of the units are off during phase 4 , and over half remain on at the end of the recording. While switch-off times are thus spread rather broadly over time, the switch-off rates are low. In addition to this far-reaching stability, commercial lighting is also highly temporally extended: beginning and ending in a partial on-state, it is the only type that is never fully off.

\section{Commercial Lighting: On-Rates of Lighting Units by Area}

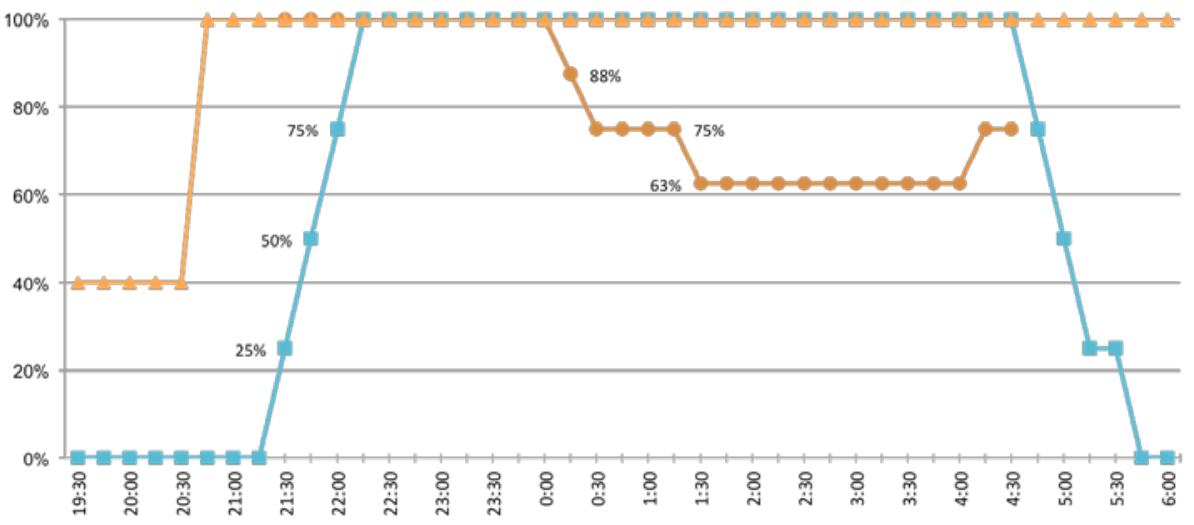

-AP Commercial $(n=8)$ -PP Commercial $(n=4)$ $=-H M$ Commercial $(n=5)$

Fig. 19: Commercial on-curves

The three areas' commercial on-curves are rather divergent - and this broad variation in temporal profiles is the reason for commercial lighting's short overall full-on phase (fig. 19): While full illumination is only reached at 22:00 at Potsdamer Platz, it already ends at midnight at Alexanderplatz. Potsdamer Platz and Hackescher Markt are akin in their extended full-on phases and lack of switch-offs during the night. Nonetheless, they are far from identical: Beginning and ending in a full-off state, Potsdamer Platz' curve is comparable to infrastructural lighting with its late but rapid switch-ons and early but rapid switch-offs. Hackescher Markt, on the other hand, is extreme in its stability and temporal extension: Its commercial lighting is switched on early and quickly and remains illuminated without exception until the end of the recording. By contrast, Alexanderplatz' commercial 
lighting sees considerable variations after midnight: It drops to ca. 60\% in phase 4, and is the sole reason for the reduction visible in the aggregate on-curve. Additionally, changes take place during phase 4 that are not visible in the on-curve: Two intermittent units are switched off and on at nearly the same time, effectively cancelling each other out - thus, while the proportion of units that remain on is stable, their composition changes.

\subsubsection{Indoor Lighting}

Indoor lighting stands out through its compact on-curve and thus its limited temporal extension (fig. 16). It is the only type to be fully off at the beginning and end of the recordings: its units begin coming on comparatively late in the evening, and are the earliest to be off in the morning. Phase 3 is short, and changes are strong: within under an hour after midnight, the on-rate drops below 50\%, further than any other type. Similarly, its phase 4 begins - and ends - 1-2 hours earlier than that of commercial or architectural lighting.

Indoor Lighting: On-Rates of Lighting Units by Area

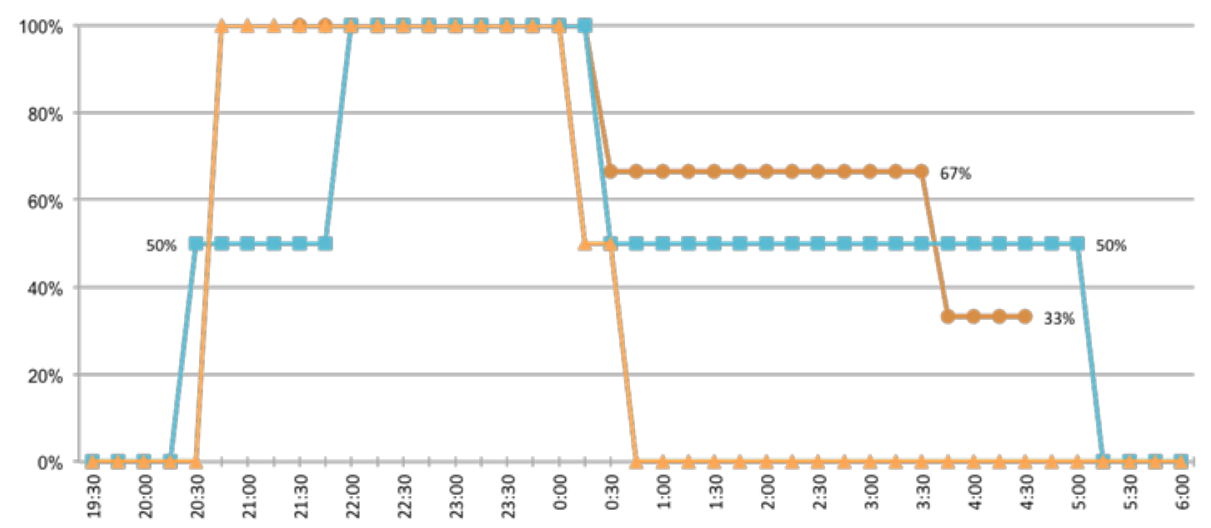

Fig. 20: Indoor on-curves

The on-curves of the three areas are fairly uniform in that they display largely similar timing in the first two dynamic phases (fig. 20). Notably, the switch-offs that occur within such a short time in phase 3 are spread over all three areas. There are, however, substantial differences in terms of stability and temporal extension: Hackescher Markt with its stable full-off situation as of 00:45 marks the one end of the spectrum Alexanderplatz marks the other with its successive and intermittent reductions.

\subsubsection{Comparison between the Types of Lighting}

Before midnight, similarities predominate among the temporal profiles of the four types of lighting - after midnight, however, differences abound in terms of the timing, speed and extent of change.

With its high uniformity across the three areas, infrastructural lighting exhibits a very strong temporal profile and clearly sets itself apart from the other three types as the only group that remains fully on throughout the night, and in which only three of the five phases are recognisable. While this extreme stability is unsurprising, it is remarkable that the infrastructural units are most reliably joined in their nightwatch by commercial lighting remaining fully alight in two of three areas, it shows little reduction during the night and a high temporal extension. This pronounced leaning toward uninterrupted and extended illumination is particularly interesting as commercial lighting is not only the largest category, but also contains two arguably rather different forms of illumination: signs and shop windows. Architectural and indoor lighting are considerably more dynamic. They are alike insofar as they exhibit strong contrasts in their on-rates, are reduced to similar extents during the night and are completely switched off before 6:00. However, while the reduction rate among architectural units is high, so is the duration of their full-on phase: the switch-off process begins late, ca. one hour after the other two dynamic types. Its strong temporal profile indicates that architectural units across the board follow similar schedules. By contrast, the overall temporal profile of indoor lighting is rather weak, indicating that there is no clear usage pattern; and with its early and far-reaching switch-offs, it is the least extended type of all. 
The proposed research design and the findings from the Berlin cases open pathways and first insights for a deeper understanding of the temporalities of high-density lightscapes. As many questions remain to be answered, the design now awaits further application and validation.

\subsection{Research Design}

With the research design, temporal lighting practices in complex lighting situations can be systematically deconstructed, described and compared. It traces changes in illumination that have been observed at more aggregate levels to their roots, namely to the individual elements of which lightscapes are composed. This detailed approach, however, brings with it a central limitation: It is hardly apt for studying the temporal profiles of large intricately lit areas such as the lightscapes of entire cities. While this is theoretically conceivable, it appears beyond fair effort and would imply questionable levels of surveillance.

The design was conceived to be easily transferrable to other places, and compatible with diverse research interests related to questions of temporality and/or artificial lighting. Such broad applicability demands a certain level of technical and conceptual simplicity. The temporality of outdoor illumination is thus studied at its most basic: by way of the lights' on/off transitions. These can easily be extracted manually, keeping the use of specialised software possible, but not mandatory, and well be compared with other temporal data. Possible changes in the lights' brightness levels are, however, disregarded. This is currently likely of limited concern in most places, but will become more relevant as more adaptable lighting technologies spread. Using temporal units of lighting as base elements focuses the analysis on the main factor of interest: temporality. However, it treats the elements of lightscapes as equals, while, in fact, they are highly varied. Weighting the units according to characteristics such as size or brightness may offer a possibility to mitigate this issue, but remains to be developed and tested. Similarly, calculating aggregate on-rates as percentages and visualising these as on-curves facilitates comparisons among different categories of lighting. It can, however, obscure overlapping changes and be deceptive when base-numbers are small, demanding heightened caution in interpretation.

The design's transferability now calls for testing: By applying it in other contexts and comparing the results among each other, insights could not only be gained regarding similarities and differences among temporalities in different locations or during different nights, but also for the further consolidation of the design itself, e.g. for prospectively complementing the design's qualitative terms for characterising temporal profiles with quantitative descriptors. Finally, by facilitating systematic comparisons among similar types of areas or lighting in different cities or countries, and among different types of areas or lighting within the same geographic and policy context, the design can provide indications of factors that temporal lighting practices may hinge on. It cannot, however, explain them: To more fully understand what determines the observed patterns, further research will invariably be necessary.

\subsection{Findings}

By applying the proposed research design to the three Berlin cases, the question was addressed of how the temporality of urban lighting is structured in these urban centres, which are similar in many respects. The observed patterns can, essentially, be traced to two types of units that reflect temporally distinct lighting practices: Firstly, all-night units, which are kept continuously illuminated throughout the night and represent the large majority (ca. 2/3) of all units. Secondly, part-night units that are switched off at some point during the night - either to remain off, as is mostly the case, or to be switched back on before daylight returns (intermittent units). The majority of units thus does not contribute to the changes visible in the lightscapes during the night: These are solely a function of the part-night units. It is (a) how their switching times are spread over the night, in combination with (b) how the units themselves are distributed across the three areas and four types of lighting, that shapes the different temporal profiles.

In each lightscape as a whole, the part-night units' switching times are neither distributed evenly nor randomly over the night. Rather, they are clustered, resulting in alternating static and dynamic phases. Midnight emerges as a temporal fault line: full illumination ends, and a ca. two-hour phase of transition begins as units are switched off. The lightscapes then once again come to rest in a partly illuminated state until the morning switch-off begins. Thus, the lightscapes will look different depending on when they are observed - not only in terms of numbers of illuminated units (these are reduced), but also in terms of their functional composition (infrastructural and commercial units become more dominant vs. architectural and indoor units), in effect making them less diverse. Further research could e.g. reveal whether midnight is a typical temporal fault line, or whether it is specific to Berlin in summer. 
The part-night units, and the points in time at which they are switched off, are also not distributed evenly across the three areas or the functional types of lighting. As a result, there are partly substantial differences between the various temporal profiles. These are more pronounced among the functional types than among the areas: The areas differ from each other more by degree, whereas the types differ in character. This becomes especially apparent as of midnight: While infrastructural and commercial units remain (nearly) fully alight, many architectural and indoor units are switched off - albeit as of rather different times. The resulting hypothesis is that - at least for Berlin's urban centres - temporal lighting practices are more closely linked to the purposes to which lights are put than to the area to which they belong. This would imply that the temporality of a lightscape is likely, at least in part, a result of its functional composition. Among the areas, differences interestingly appear greater between Alexanderplatz with its strong dynamics on the one hand, and the other two considerably more stable areas on the other - rather than between Alexanderplatz and Potsdamer Platz as comparatively bright, large-scale areas, vs. more mundane Hackescher Markt, which was chosen as a contrast example. What is at the root of the observed differences between areas, types and individual units remains an open question, and points toward the need for further inquiry: for one, by testing other forms of classification with larger empirical bases to determine their explanatory power, and for another by investigating the temporal rationales of the actors who determine the lights' schedules.

\section{Conclusions}

The research design presented in this article fills a gap in the toolbox of interdisciplinary lighting studies by offering a means of systematically describing and contrasting temporal lighting practices. Geared toward detailed analyses of complex lightscapes such as those of urban centres, it complements existing approaches that take a larger-scale view of the temporal $[12 ; 13]$ and of the spatial [e.g. $10 ; 18 ; 19 ; 20]$ structure of urban lightscapes. The design is transferrable to different contexts and adaptable to different research interests. As such, it contributes to the development of forms of lighting cartography that are much-needed for better understanding, communicating about and managing the usage of artificial lighting.

The findings from the Berlin areas show that their lightscapes' compositions change significantly throughout the night. This has important implications for assessments of lightscapes based on data collected at specific points in time, e.g. via aerial imagery: depending on when it is collected, results will differ. As - at least in Berlin on weeknights - phases of illumination are clearly discernible, time-windows can be identified during which it is likely that most lights are on (са. 22:00-00:00), and during which a largely stable part-on state can be observed (ca. 2:00-4:00). Once identified, such time-windows can be targeted in further research. For example, comparative analyses of photographs of the entire city during these two phases can provide pointers toward overall switch-off patterns that are beyond the scope of the here-presented small-scale design.

For the development of temporally oriented lighting policies such as those in France [21], results such as those presented here can provide an empirical underpinning for debating and defining lighting curfews, as well as for monitoring the effectiveness of regulations. Going further, comparisons of the temporal profiles of lighting with those of other urban functions (e.g. opening hours or public transport schedules) could provide valuable insights on the relation between lighting rhythms and activity patterns [22 is a first exploration]. Such knowledge provides a basis of departure for further investigating the rationales of the actors behind the lights' switches who will, in the end, be the addressees of regulations.

\section{Acknowledgements}

I would like to thank Dietrich Henckel for the many inspiring discussions on the temporality of cities and lighting which led to this work, Philipp Elgert and Franziska Ottrembka for recording and assembling the time lapse videos, and all others who supported the development of this paper through their valuable feedback: Christine Preiser, Gunnar Wehrhahn, William Straw, Michaela Christ and the anonymous reviewers.

\section{$7 \quad$ References}

[1] Hölker, F., Moss, T., Griefahn, B., Kloas, W., Voigt, C. C., Henckel, D., ... Tockner, K. (2010). The Dark Side of Light: A Transdisciplinary Research Agenda for Light Pollution Policy. Ecology and Society, 15(4), 13. http://www.ecologyandsociety.org/vol15/iss4/art13/

[2] Gaston, K. J., Gaston, S., Bennie, J., \& Hopkins, J. (2014). Benefits and costs of artificial nighttime lighting of the environment. Environmental Reviews, 23(1), 14-23. https://doi.org/10.1139/er-2014-0041 
[3] Pottharst, M., \& Wukovitsch, F. (2015). The Economics of Night-Time Illumination. In J. Meier, U. Hasenöhrl, K. Krause, \& M. Pottharst (Eds.), Urban Lighting, Light Pollution and Society (pp. 203-223). Routledge.

[4] Falchi, F., Cinzano, P., Duriscoe, D., Kyba, C. C. M., Elvidge, C. D., Baugh, K., ... Furgoni, R. (2016). The new world atlas of artificial night sky brightness. Science Advances, 2(6), e1600377. https://doi.org/10.1126/sciadv.1600377

[5] Kyba, C. C. M., Kuester, T., Miguel, A. S. de, Baugh, K., Jechow, A., Hölker, F., ... Guanter, L. (2017). Artificially lit surface of Earth at night increasing in radiance and extent. Science Advances, 3(11), e1701528. https://doi.org/10.1126/sciadv.1701528

[6] Henckel, D., \& Moss, T. (2015). Towards a Brighter Future? Conclusions for Lighting Research and Policy. In J. Meier, U. Hasenöhrl, K. Krause, \& M. Pottharst (Eds.), Urban Lighting, Light Pollution and Society (pp. 299-303). Routledge.

[7] Bará, S. (2016). Anthropogenic disruption of the night sky darkness in urban and rural areas. Open Science, 3(10), 160541. https://doi.org/10.1098/rsos.160541

[8] Ges, X., Bará, S., García-Gil, M., Zamorano, J., Ribas, S. J., \& Masana, E. (2017). Light pollution offshore: zenithal sky glow measurements in the Mediterranean coastal waters. http://arxiv.org/abs/1705.02508

[9] Kyba, C. C. M., Tong, K. P., Bennie, J., Birriel, I., Birriel, J. J., Cool, A., ... Gaston, K. J. (2015). Worldwide variations in artificial skyglow. Scientific Reports, 5. https://doi.org/10.1038/srep08409

[10] Kyba, C. C. M., Garz, S., Kuechly, H., de Miguel, A. S., Zamorano, J., Fischer, J., \& Hölker, F. (2014). High-Resolution Imagery of Earth at Night: New Sources, Opportunities and Challenges. Remote Sensing, 7(1), 1-23. https://doi.org/10.3390/rs70100001

[11] Sánchez de Miguel, A. (2015). Spatial, Temporal and Spectral Variation of Light Pollution and its Sources: Methodology and Results. Universidad Complutense de Madrid.

[12] Dobler, G., Ghandehari, M., Koonin, S. E., Nazari, R., Patrinos, A., Sharma, M. S., ... Wurtele, J. S. (2015). Dynamics of the urban lightscape. Information Systems, 54, 115-126. https://doi.org/10.1016/j.is.2015.06.002

[13] Bará, S., Rodríguez-Arós, Á., Pérez, M., Tosar, B., Lima, R. C., de Miguel, A. S., \& Zamorano, J. (2017). Estimating the relative contribution of streetlights, vehicles and residential lighting to the urban night sky brightness. http://arxiv.org/abs/1706.04458

[14] Oxford Dictionaries. (n.d.). Landscape - definition of landscape in English. Oxford Dictionaries. https://en.oxforddictionaries.com/definition/landscape

[15] Senatsverwaltung für Stadtentwicklung und Umwelt Berlin (2015). Stadtbild Berlin: Lichtkonzept. Handbuch.

[16] Krause, K. (2015). Regulating Urban Lighting: Prospects for Institutional Change. In J. Meier, U. Hasenöhrl, K. Krause, \& M. Pottharst (Eds.), Urban Lighting, Light Pollution and Society (pp. 125-140). Routledge.

[17] ISR. (2011). Zeiteffiziente Stadt - Zeitgerechte Stadt (Project Report). TU Berlin, Institut für Stadt- und Regionalplanung.

[18] Kuechly, H. U., Kyba, C. C. M., Ruhtz, T., Lindemann, C., Wolter, C., Fischer, J., \& Hölker, F. (2012). Aerial survey and spatial analysis of sources of light pollution in Berlin, Germany. Remote Sensing of Environment, 126, 39-50. https://doi.org/10.1016/j.rse.2012.08.008

[19] Hale, J. D., Davies, G., Fairbrass, A. J., Matthews, T. J., Rogers, C. D. F., \& Sadler, J. P. (2013). Mapping Lightscapes: Spatial Patterning of Artificial Lighting in an Urban Landscape. PLoS ONE, 8(5), e61460. https://doi.org/10.1371/journal.pone.0061460

[20] ISR. (2013). LichtGestalten: Analyse-, Gestaltungs-, und Konfliktpotenziale (Project Report). TU Berlin, Institut für Stadt- und Regionalplanung.

[21] République Francaise (2013). Arrêté du 25 janvier 2013 relatif à l'éclairage nocturne des bâtiments non résidentiels afin de limiter les nuisances lumineuses et les consommations d'énergie.

[22] Meier, J., \& Henckel, D. (2017). Illuminating an Urban Zone of Extended Activity: An Exploration into Temporal Profiles of Urban Functions, Public Transport and Artificial Lighting. In G. Drevon, L. Gwiazdzinski, \& O. Klein (Eds.), Chronotopies / Chronotopics. Lecture et écriture des mondes en mouvement / Readings and writings on a world in movement (pp. 128-135). Elya editions. 